5-1-2009

\title{
Parameter estimation validity and relationship robustness: A comparison of telephone and internet survey techniques
}

\author{
Cheryl C. Bracken
}

Cleveland State University, c.bracken@csuohio.edu

Leo W. Jeffres

Cleveland State university, I.jeffres@csuohio.edu

Kimberly Neuendorf

Cleveland State University, K.NEUENDORF@csuohio.edu

Pakd Ał Ałkjand additional works at: https://engagedscholarship.csuohio.edu/clcom_facpub

Part of the Communication Commons

How does access to this work benefit you? Let us know!

\section{Publisher's Statement}

NOTICE: this is the author's version of a work that was accepted for publication in Telematics and Informatics. Changes resulting from the publishing process, such as peer review, editing, corrections, structural formatting, and other quality control mechanisms may not be reflected in this document. Changes may have been made to this work since it was submitted for publication. A definitive version was subsequently published in Telematics and Informatics, 26, 2, 05-01-2009, 10.1016/j.tele.2008.03.001

\section{Recommended Citation}

Bracken, C. C., Jeffres, L. W., Neuendorf, K. A., \& Atkin, D. (2009). Parameter estimation validity and relationship robustness: A comparison of telephone and internet survey techniques. Telematics and Informatics, 26(2), 144-155. https://doi.org/10.1016/j.tele.2008.03.001

This Article is brought to you for free and open access by the School of Communication at EngagedScholarship@CSU. It has been accepted for inclusion in Communication Faculty Publications by an authorized administrator of EngagedScholarship@CSU. For more information, please contact library.es@csuohio.edu. 


\section{Parameter estimation validity and relationship robustness: A comparison of telephone and internet survey techniques}

Cheryl Campanella Bracken, Leo W. Jeffres, Kimberly A. Neuendorf, David Atkin

\section{Introduction}

With the expansion of telecommunication and online technologies for the purpose of survey administration, the issue of measurement validity has come to the fore. ldeally, such surveys are designed to provide a sample that enables the researcher to reach valid and reliable conclusions that can be generalized to a larger population. Thus, surveys must be planned and administered in a way that enables researchers to identify and prevent sources of selection and information bias, including those based on survey modality, e.g., telephone administration (see Kemph and Remington, 2007).

The proliferation of automated audio services and computer-based survey techniques (e.g., Skalski et al., 2006) has been matched by a corresponding denigration of the quality of traditional phone survey data, most notably as an outcome of 
falling response rates (Stempel et al., 2003). Kemph and Remington (2007) report, for instance, a steady decline in response rates for telephone surveys at one University of Michigan survey center, from $72 \%$ in 1979 to a low of $48 \%$ in 2003.

This trend, combined with the introduction of screening technologies and answering machines, represents a barrier to the proper execution of survey research (e.g., Bassili, 2000). Whereas the question was once, "can technology-assisted surveys achieve the same level of validity as traditional phone surveys?", the question now becomes, "what are the relative advantages and disadvantages of technology-assisted and phone surveys?" Each survey modality presents its own challenges and opportunities, and this paper begins to explore some of these tradeoffs, alongside their implications for telematic survey practitioners.

\subsection{Review of literature}

There is little previous research that offers comparisons across survey administration modalities (e.g., phone vs. online survey methods). The current literature mainly focuses on response rates (Bassili, 2000; Bennett and Steel, 2000; Cho and LaRose, 1999; Dillman, 2000; Fowler et al., 1998; Goyder, 1985; Herzog and Rodgers, 1988). The questioning of data validity based on survey mode is less common (see Atkin and LaRose, 1994b; Bates and Harmon, 1993; Bonnel and LeNir, 1998; Jones and Pitt, 1999; Xu et al., 1993). Increases in the use of web-based surveys have lead researchers to question the validity of Internet data (e.g., Bates and Harmon, 1999). Similarly, the promotion of self-selected listener opinion surveys (SLOPs) which are widely used by the media - has been criticized (Atkin and LaRose, 1994a,b; Gollin, 1992; Kamerer and Bergen, 1995; LaRose and Atkin, 1992; Neuendorf et al., 1998, 2002). However, Witte et al. (2000) argue that Internet-based survey research can provide meaningful data that can be generalized to Internet users in general populations. This study will provide further insight into the validity of telephone and Internet survey data, and explore whether or not the robustness of relationships between variables varies by survey mode.

Present-day concerns about the validity of online polling recall those surrounding the Literary Digest poll in the 1936 US Presidential election. In that classic case of parameter mis-estimation, the Digest's voluminous sample of 2 million readers drawn from a sampling frame of 10 million names derived from ownership logs of telephones and automobiles - predicted an Alf Landon victory over President Franklin Roosevelt. LaRose and Atkin (1994b, p. 218) maintain that, "because wealthy Republicans were more likely to adopt the telephone and express anti-Roosevelt sentiments, the poll failed to detect the impending Democratic landslide." At the time, however, the Digest was perplexed about "what went wrong with the polls?", as outlined in their editorial below:

We were getting better cooperation in what we have always regarded as a public service from Republicans than we were getting from Democrats. Do Republicans live nearer to mailboxes? Do Democrats generally disapprove of straw polls? (cited in Atkin and LaRose, 1994b, p. 219).

This case in fact provides a textbook example of parameter mis-estimation stemming from a poor sampling frame, one thrown off by the upscale socio-demographic/political byproducts of technology adoption. Having drawn a sample from an upscale universe of product adopters - overrepresenting wealthier, more conservative Republican voters - the Digest survey pointed to relationships that were insufficiently robust, prompting the magazine to incorrectly predict a landslide in the opposite direction.

As Neuendorf et al. (2002) suggest, such demographic skews are actually consistent with diffusion of innovations theory, which predicts that the adoption of new telecommunication innovations is resource-driven. The telephone was in roughly a third of US households during the 1930s, and the Internet available to perhaps twice that number 70 years later (Brown, 2006). Rogers' (2003) review of diffusion research links adoption of these and other innovations to such social locators as income and education as well as social participation, greater exposure to mass and interpersonal communication channels.

More recently, Internet sites have proven a popular vehicle for promotional as well as scientific polls - with hundreds of individual lines promoted in dedicated websites - and scores of others noted in topical listing services. When the Internet was a relatively new innovation, Bates and Harmon (1991) noted an overrepresentation of activist sentiment in videotext surveys (see also Adler and Clark, 2001). Studies of Internet diffusion suggest that adopters were initially higher in social status (e.g., Atkin et al., 1998), lending rise to concerns over the validity of online samples, symptomatic of a larger "digital divide" which may be leaving African Americans behind (e.g., Weiser, 2000). Other work suggests that the Internet has reached the "flat" part of its diffusion curve in recent years, having been used by roughly $70 \%$ of Americans on a given day (Pew, 2007). Researchers are thus seeing a leveling of differences between adopters and non-adopters, consistent with adoption patterns for mature innovations, according to diffusion theory (e.g., Krcmar and Strizhakova, 2007). The realization of the Internet as a mature medium implies a need to revisit some of the earlier research approaches that examined the characteristics of telephone subscribers which, in turn, can provide a useful baseline for considering survey sampling dynamics in each modality.

Neuendorf et al. (2002) note that, since so much diffusion research has been conducted via telephone, telephone adoption itself represents more of a constant than a variable in diffusion study databases. LaRose and Atkin $(1988,1992)$ maintain that the telephone has long been taken for granted as a relatively low-technology, culturally familiar, two-way voice medium. Behavioral perspectives on phone adoption were rare, or steeped in the annals of the Bell system (Dunn et al., 1971), with early work finding that adoption was related to age, income, education, employment, urban residence, and status as head of 
household (e.g., Mahan, 1979; Perl, 1978; Taylor, 1980). Mahan (1979) found that those less likely to have a phone included minority homes and homes with young children, which were also identified by Perl (1978), along with male-headed, singleperson, and Southern as well as spouse-absent households. Many of these differences had leveled by the 1980s (e.g., LaRose and Atkin, 1988; Train et al., 1987), as those without a household phone were still more likely to be renters (Thornberry and Massey, 1988), unemployed (Tucker et al., 2004), non-white minorities, less educated and living in rural areas (Ford, 1998). By 1990 , the telephone was available to $92-93 \%$ of American homes, ranking among the most widely diffused media in the US (Bates et al., 2002).

\subsection{Research questions}

In the new millennium, the Internet stands poised to transform survey research in the same way that the telephone did in the last century (e.g.. Skalski et al., 2006). The notion of sample data as representative of population parameters can thus be viewed in a new light in this era of technology interposition. New methods of approximating "randomness" are being explored, as in the case of marketing research firms using very large "standing" online samples to represent target populations. Looking at the best possible parameter information (e.g., US Census information and voting activity), we may compare the two methods as to their current abilities to match population parameters:

RQ1: What are the apparent levels of validity of phone and online survey measures (using "known" population parameters as reference criteria)?

Earlier analyses have tested various communication theories (e.g., spiral of silence) with the two data sets (Jeffres et al., 2001, 2007), locating relationships that were robust across the two samples, and discovering other relationships that held only for one sample and not the other (e.g., for the phone survey but not the online survey). Although actual testing of such theoretical perspectives lies outside the present study's focus, the pertinent results from that work demonstrated that media exposure variables figure prominently in the Internet survey and not at all in the phone survey. Now, we expand our investigation to a wider range of relationships derived from theories of cognitive processing, political socialization, agenda-setting, and selective perception.

The notion of robustness applied does not encompass conventional examinations of statistical robustness, that is, to what degree a given statistical procedure can tolerate violations of assumptions (Cohen et al., 2003). Rather, we use the logically parallel concept of relationship robustness - i.e., the degree to which relationships among variables are evident across time periods, populations, or research modalities.

For both data sets, we are able to assess such relationships as the prediction of political knowledge and political attitudes from social categories, media use, and political partisanship. The present study examined the relationship between partisanship and attitudes toward presidential advertising during the 2000 campaign. In particular, we inquire:

RQ2: What types of relationships tend to enjoy robustness for phone and online survey administrations? Which types do not?

Limitations to robustness of relationships are expected to the extent that phone and Internet adoption correlates are also influential in such relationships. In this study, the very modalities of delivery of survey instruments are examined for their impact on theoretic relationship robustness. A lack of robust findings would, importantly, call into question the validity of thousands of survey research outcomes over decades of mediated survey data collection.

Additional comparisons may be made after the two samples are "matched" for relevant social categories via weighting techniques commonly used for non-random online surveys. Thus:

$\mathrm{RQ3}$ : Do social category weighting techniques increase the robustness of findings? Is there an increase for some types of relationships and not for others?

Robustness of relationships in this instance may indicate the efficacy of identifying and controlling for critical adoption correlates for survey delivery technologies.

These exploratory analyses will shed light on the comparative validity of phone and online surveys in a contemporary media environment that both welcomes communication activity in new ways (e.g., note the fast-expanding online population) and sets up technological barriers to other communication exchanges (e.g., note the growing variety of telephone adjuncts designed to protect the homeowner from unwanted calls, such as caller ID and privacy call). The research questions proposed here will be examined in a series of studies described in the following section.

\section{Method}

Two surveys were conducted in the two and a half weeks leading up to the 2000 presidential election. One survey was conducted in a metropolitan area of the Midwest, with interviews of 505 adults using a computer-aided telephone-interviewing (CATI) system. The second was a national survey of 2172 respondents conducted over the Internet by a commercial research firm that sends requests to a diverse set of potential respondents, who logged onto the survey site to participate. The interview schedule for the telephone survey and the Internet instrument followed parallel forms, with no differences in 
wording other than those created by the unique nature of the formats. Thus, the Internet interview included some matrices to display items that were administered serially in the telephone survey.

For RQ1 the demographic data collected from both studies was compared to county and national Census 2000 demographic information when possible. Information on national Internet populations was obtained from the MediaMark research company. The results from the CATI and Internet survey are compared to the Census 2000 national and county and Internet national demographic data to confirm representativeness.

\section{Dependent variables}

For $\mathrm{RQ} 2$ and $\mathrm{RQ} 3$ the chosen dependent variables are political knowledge, and closeness to candidates on political issues addressed in the 2000 campaign. Specifically the political issues are taxes, education, environment, social security, abortion, gun control, and foreign policy. The respondents were asked to respond the each issue using the response scale $0=$ "Closest to Bush" to 10 = "Closest to Gore."

A political knowledge scale was created from the variables that tested respondents' knowledge. The variables included in the scale are "Can you tell me where is Kosovo located?". "Which of the presidential or vice presidential candidates is the son of a former US Senator?", "The Nobel Peace Prize this year was won by a political leader from which of the following countries?", "Who is running for the US Senate in New York against Hillary Clinton?", and "Which of the presidential candidates supports school vouchers?" The respondents were instructed to answer the questions and were not given response options. The question asking about the New York state Senate race was the exception and provided five response options.

In order to address Research Question 3, a number of different weightings were executed on the CATI and on the Internet data sets. Those demographic indicators for which both survey data and US Census information (www.census.gov) were available were used as weighting factors. Adjustments of the CATI survey to match estimates of local county parameters included gender, age, race, and educational level; Census 2000 figures were used as the targets for all except education, which was not available for 2000 (1990 figures were used). For the matching of the Internet survey to US national parameters, the weighting factors available were gender, age, race, household size, marital status, educational level, and household income. All indicators were Census 2000 figures. And for the matching of the Internet survey data to those provided by the US Census Bureau for Online users in 2000 , the weighting factors were gender, age, household size, marital status, educational level, and household income. ${ }^{1}$

Given the limitation of the SPSS program to a single weighting factor, the multiple weighting factors in this study were multiplied to produce a single weight. This obviously assumes little or no relationship among factors, which proved to be a safe assumption for the CATI data, but not for the Internet data. Thus, the weighting functions for the two Internet sample adjustments were not optimal. (We await more sophisticated algorithms that may allow complex weighting functions with ease.)

It should be noted that we did execute weightings to match the CATI data to national Census parameter estimates. These weightings differed very little from the CATI-to-local county weights, the main difference being a racial shift, with the county containing fewer Asian residents and more African-American residents than the country at large. The CATI-to-National adjustment resulted in predictive regression results that were nearly identical to those for the CATI-to-county adjustment, and so the former analyses are not reported here.

After each of the parametric adjustments was executed, stepwise multiple regressions were run again, predicting political knowledge and a variety of political attitudes from demographics and media behaviors. The results of selected multiple regression analyses are presented in Tables $6-8$.

\section{Results}

RQ1 explored the apparent levels of external validity of both the phone and online survey measures. Data pertaining to demographic characteristics of each survey modality are included in Tables 1-5.

With regard to respondent age, the results show that the CATI survey's $18-40,41-60$, and $61+$ year-old sample is much more representative of the population from which it draws than is the Internet sample. Specifically, the gender of the respondents in the sample (see Table 1) from the CATI survey is comprised of $43.4 \%$ males and the county census reports a $47.2 \%$ male cohort. By comparison, the Internet survey reports a $26.7 \%$ male cohort and the national census indicates a constituency that is $49.1 \%$ male (see Table 1 ).

\footnotetext{
${ }^{1}$ For the CATI-to-(local) County matching, the following variable groupings were used: gender (male, female), age (18-40, 41-60, 61+), race (AfricanAmerican, White, Asian, American Indian, Mixed, and Others), and education (grade school, some high school, high school graduate/some college, college graduate, advanced college). For the Internet-to-National figures matching, the following variable groupings were used: gender (male, female), age (18-40, 4160,61+), race (African-American, White, Asian, American Indian, Mixed, and Other), household size (1-2,3-4,5+), marital status (married, divorced, widowed, separated, never married), education (grade school, some high school, high school graduate, some college, college graduate, advanced college), and household income (less than $\$ 10,000, \$ 10,000-20,000, \$ 20,000-30,000, \$ 30,000-40,000, \$ 40,000-50,000, \$ 50,000-75,000, \$ 75,000-100,000, \$ 100,000+$ ). For the Internetto-Online data matching, the following variable groupings were used: gender (male, female), age (18-20, 21-30, 31-40, 41-50, 51-60, 61-70, 71+), household size (1-2,3-4,5+), marital status (married, single, other), education (grade school through some college, college graduate+), and household income (less than $\$ 50,000, \$ 50,000-75,000, \$ 75,000+)$. In the case of age, the categories for the CATl and Internet measures did not match up precisely with those for the Census information, and a process of extrapolation was used.
} 
Table 1

Percentage and frequencies of gender in phone and national populations

\begin{tabular}{|c|c|c|c|c|}
\hline & \multicolumn{4}{|l|}{ Gender } \\
\hline & \multicolumn{2}{|l|}{ Male } & \multicolumn{2}{|l|}{ Female } \\
\hline & Percentage & $n$ & Percentage & $n$ \\
\hline CATl survey & 43.4 & 219 & 56.6 & 286 \\
\hline Census county data & 47.2 & 658,481 & 52.8 & 735,497 \\
\hline Internet survey & 26.7 & 579 & 73.3 & 1592 \\
\hline National census & 49.1 & $138,053,563$ & 50.9 & $143,368,343$ \\
\hline
\end{tabular}

Table 2

Percentage and frequencies of age in phone, internet and national populations

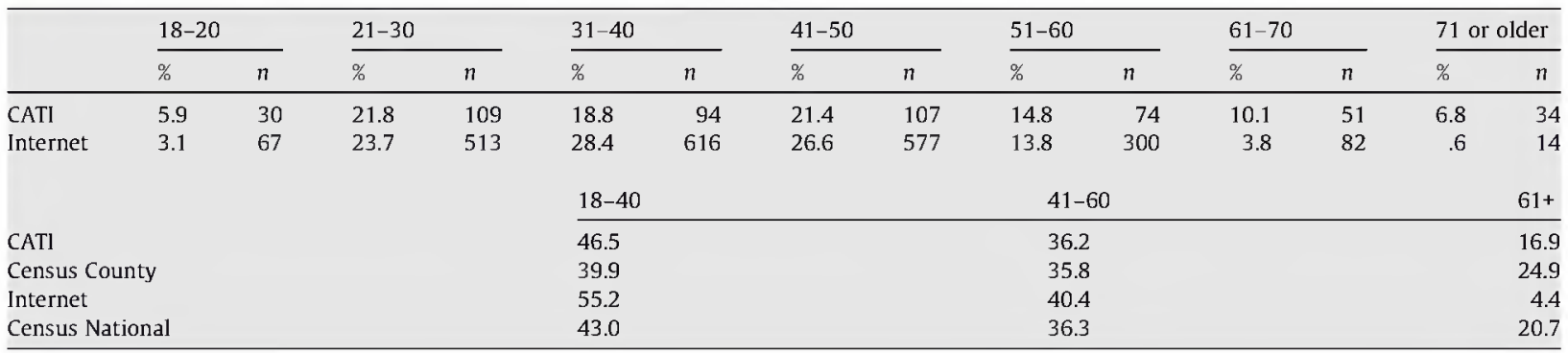

Table 3

Comparison of mean of household size

\begin{tabular}{ll}
\hline CATI & Mean \\
Census County & 2.74 \\
Internet & 2.39 \\
Census National & 2.92 \\
\hline
\end{tabular}

Table 4

Percentage and frequencies of racial identity

\begin{tabular}{|c|c|c|c|c|c|c|c|c|c|c|c|c|}
\hline & \multicolumn{2}{|c|}{ African American } & \multicolumn{2}{|c|}{ White/Caucasian } & \multicolumn{2}{|c|}{ Asian } & \multicolumn{2}{|c|}{ American Indian } & \multicolumn{2}{|c|}{ Mixed } & \multicolumn{2}{|c|}{ Other } \\
\hline & $\%$ & $n$ & $\%$ & $n$ & $\%$ & $n$ & $\%$ & $n$ & $\%$ & $n$ & $\%$ & $n$ \\
\hline $\begin{array}{l}\text { CATI } \\
\text { Census }\end{array}$ & 20.4 & 103 & 65.1 & 322 & 1.6 & 8 & 1.0 & 5 & 2.8 & 14 & 4.8 & 24 \\
\hline County & 27.4 & 382,634 & 67.4 & 938,863 & 1.8 & 25,245 & 0.2 & 2,529 & 1.7 & 23,407 & 1.5 & 20,962 \\
\hline Internet & 2.7 & 59 & 88.6 & 1923 & 1.8 & 38 & 1.1 & 23 & 2.0 & 44 & 1.2 & 26 \\
\hline Census & & & & & & & & & & & & \\
\hline National & 12.3 & $34,658,190$ & 75.1 & $211,460,626$ & 3.6 & $10,242,998$ & 0.9 & $2,475,956$ & 2.4 & $6,826,228$ & 5.5 & $15,359,079$ \\
\hline
\end{tabular}

FN: Hispanic or Latino background was not included in categories based on U.S. census.

Additionally, racial identity for the CATI is more representative than the Internet survey (see Table 4). Using the two largest groups in the CATI survey, the African-American racial identity comprised 20.4 of the CATI sample and 27.4 of the County census. Caucasians made up 65.1\% of the CATI sample and 67.4 of the County census. In the Internet survey, by comparison, African-Americans only comprised $2.7 \%$ of the sample but account for $12.3 \%$ in the national census. Caucasians were over represented in the Internet sample, comprising $88.6 \%$ of respondents, but only accounting for $75.1 \%$ in the national census (see Table 4).

RQ2 investigated the types of relationships that tend to enjoy robustness for phone and online survey administrations and which do not. All of the dependent variables were tested using stepwise multiple regression. However, only three dependent variables (political knowledge, gun control and foreign policy) are presented here, as the authors feel they typify the trend seen in the other dependent variables. For data collected via the CATI on political knowledge (Table 6), $23 \%$ of the variance was explained by eight variables: income, age, gender, political party affiliation, newspaper, books, magazine, and video viewing. Twenty-one percent of the variance was explained for gun control (Table 7) by three of the variables: gender, education, and viewing TV news. In Table $8,24 \%$ of the variance in foreign policy was explained by three variables: Political party 
Table 5

Frequencies, percentages, means and standard deviation of variables included in multiple regression

\begin{tabular}{|c|c|c|c|c|c|c|c|c|}
\hline & \multicolumn{4}{|l|}{ CATl } & \multicolumn{4}{|c|}{ Internet } \\
\hline & $\%$ & $n$ & $M$ & SD & $\%$ & $n$ & $M$ & SD \\
\hline \multicolumn{9}{|l|}{ Age } \\
\hline $18-20$ & 6.0 & 30 & & & 3.1 & 67 & & \\
\hline $21-30$ & 21.8 & 109 & & & 23.7 & 513 & & \\
\hline $31-40$ & 18.8 & 94 & & & 28.4 & 616 & & \\
\hline $41-50$ & 21.4 & 107 & & & 26.6 & 577 & & \\
\hline $51-60$ & 14.8 & 74 & & & 13.8 & 300 & & \\
\hline $61-70$ & 10.2 & 51 & & & 3.8 & 82 & & \\
\hline 71 or older & 6.8 & 34 & & & 0.6 & 14 & & \\
\hline \multicolumn{9}{|l|}{ Education } \\
\hline Completed grade school & 1.6 & 8 & & & 0.2 & 4 & & \\
\hline Some high school & 6.2 & 31 & & & 1.2 & 25 & & \\
\hline Completed high school & 19.9 & 100 & & & 16.3 & 354 & & \\
\hline Some college & 36.9 & 185 & & & 41.1 & 892 & & \\
\hline College graduate & 23.3 & 117 & & & 30.3 & 657 & & \\
\hline Advanced college degree & 12.2 & 61 & & & 11.0 & 239 & & \\
\hline \multicolumn{9}{|l|}{ Ethnicity } \\
\hline Black/African-American & 20.8 & 103 & & & 2.7 & 59 & & \\
\hline White/Caucasian & 65.1 & 322 & & & 88.7 & 1923 & & \\
\hline Hispanic & 3.8 & 19 & & & 2.5 & 55 & & \\
\hline Asian & 1.6 & 8 & & & 1.8 & 38 & & \\
\hline American Indian & 1.0 & 5 & & & 1.1 & 23 & & \\
\hline Mixed & 2.8 & 14 & & & 2.0 & 44 & & \\
\hline Other & 4.8 & 24 & & & 1.2 & 26 & & \\
\hline \multicolumn{9}{|l|}{ Income } \\
\hline$\$ 10,000$ or less & 4.9 & 22 & & & 3.8 & 82 & & \\
\hline$\$ 10,001-20000$ & 8.1 & 36 & & & 7.5 & 159 & & \\
\hline$\$ 20,001-30,000$ & 19.0 & 85 & & & 13.0 & 276 & & \\
\hline$\$ 30,001-40,000$ & 17.2 & 77 & & & 17.3 & 368 & & \\
\hline$\$ 40,001-50,000$ & 11.9 & 53 & & & 14.1 & 300 & & \\
\hline$\$ 50,001-75,000$ & 19.9 & 89 & & & 24.2 & 515 & & \\
\hline$\$ 75,001-100,000$ & 9.2 & 41 & & & 11.4 & 243 & & \\
\hline More than $\$ 100,000$ & 9.8 & 44 & & & 8.8 & 187 & & \\
\hline \multicolumn{9}{|l|}{ Gender } \\
\hline Male & 4.34 & 219 & & & 26.7 & 579 & & \\
\hline Female & 73.3 & 1592 & & & 56.6 & 286 & & \\
\hline \multicolumn{9}{|l|}{ Political identification } \\
\hline Strong democrat & 26.9 & 132 & & & 12.2 & 264 & & \\
\hline \multicolumn{9}{|l|}{ Lean towards } \\
\hline Democrat & 22.9 & 112 & & & 23.7 & 513 & & \\
\hline Independent & 26.9 & 132 & & & 25.5 & 552 & & \\
\hline \multicolumn{9}{|l|}{ Lean towards } \\
\hline Republican & 12.4 & 61 & & & 19.9 & 431 & & \\
\hline Strong republican & 10.8 & 53 & & & 4.4 & 96 & & \\
\hline Political knowledge & & & 2.46 & 1.58 & & & 1.94 & 1.21 \\
\hline Taxes & & & 5.48 & 3.45 & & & 4.68 & 3.58 \\
\hline Environment & & & 6.42 & 2.90 & & & 5.48 & 3.34 \\
\hline Education & & & 6.10 & 3.32 & & & 5.01 & 3.61 \\
\hline Social security & & & 6.36 & 3.38 & & & 5.10 & 3.67 \\
\hline Gun control & & & 5.89 & 3.24 & & & 4.91 & 3.51 \\
\hline Abortion & & & 5.68 & 3.26 & & & 5.30 & 3.73 \\
\hline Foreign policy & & & 5.66 & 3.00 & & & 4.89 & 3.26 \\
\hline Hours view TV & & & 2.68 & 2.26 & & & 2.89 & 2.50 \\
\hline \multicolumn{9}{|l|}{ Frequency of viewing TV news } \\
\hline Several times a day & 8.7 & 46 & & & 11.3 & 303 & & \\
\hline About once a week & 10.8 & 58 & & & 9.5 & 254 & & \\
\hline 5 or 6 days a weeks & 9.4 & 50 & & & 10.0 & 268 & & \\
\hline 3 of 4 days a week & 6.6 & 35 & & & 6.3 & 169 & & \\
\hline 1 or 2 days a week & 39.1 & 208 & & & 42.5 & 1137 & & \\
\hline Less often than that & 25.4 & 135 & & & 20.3 & 542 & & \\
\hline Hours listen to radio & & & 2.06 & 2.75 & & & 2.05 & 2.58 \\
\hline \multicolumn{9}{|l|}{ Days read newspaper } \\
\hline None & 15.2 & 81 & & & 17.3 & 463 & & \\
\hline 1 day & 15.9 & 85 & & & 15.5 & 416 & & \\
\hline
\end{tabular}




\begin{tabular}{|c|c|c|c|c|c|c|c|c|}
\hline & \multicolumn{4}{|l|}{ CATI } & \multicolumn{4}{|c|}{ Internet } \\
\hline & $\%$ & $n$ & $M$ & SD & $\%$ & $n$ & $M$ & $\mathrm{SD}$ \\
\hline 2 days & 6.7 & 36 & & & 11.2 & 299 & & \\
\hline 3 days & 8.6 & 46 & & & 6.8 & 182 & & \\
\hline 4 days & 6.3 & 33 & & & 4.6 & 124 & & \\
\hline 5 days & 5.4 & 29 & & & 4.8 & 129 & & \\
\hline 6 days & 2.8 & 15 & & & 3.8 & 102 & & \\
\hline Everyday & 39.1 & 209 & & & 36.6 & 962 & & \\
\hline \multicolumn{9}{|c|}{ Number of magazines read regularly } \\
\hline None & 21.3 & 112 & & & 13.9 & 371 & & \\
\hline 1 & 15.7 & 83 & & & 8.2 & 217 & & \\
\hline 2 & 21.1 & 113 & & & 23.9 & 637 & & \\
\hline 3 & 18.3 & 96 & & & 19.3 & 513 & & \\
\hline 4 & 9.8 & 52 & & & 12.7 & 339 & & \\
\hline 5 & 4.8 & 25 & & & 9.2 & 244 & & \\
\hline $6-10$ & 2.9 & 15 & & & 9.0 & 241 & & \\
\hline $11-20$ & 5.1 & 27 & & & 1.8 & 47 & & \\
\hline 21 or more & 0.5 & 3 & & & 2.0 & 54 & & \\
\hline \multicolumn{9}{|c|}{ Books read in last 6 months } \\
\hline None & 24.1 & 128 & & & 19.1 & 512 & & \\
\hline 1 & 18.0 & 96 & & & 11.7 & 314 & & \\
\hline 2 & 13.3 & 71 & & & 14.0 & 373 & & \\
\hline 3 & 10.1 & 54 & & & 9.8 & 261 & & \\
\hline 4 & 4.8 & 26 & & & 8.0 & 214 & & \\
\hline 5 & 4.4 & 24 & & & 7.4 & 197 & & \\
\hline $6-10$ & 10.0 & 53 & & & 14.5 & 387 & & \\
\hline $11-20$ & 6.6 & 35 & & & 8.8 & 235 & & \\
\hline 21 or more & 8.7 & 46 & & & 6.7 & 179 & & \\
\hline \multicolumn{9}{|c|}{ Videos viewed in last 6 months } \\
\hline None & 37.8 & 201 & & & 46.9 & 1248 & & \\
\hline 1 & 12.0 & 64 & & & 8.3 & 220 & & \\
\hline 2 & 12.5 & 66 & & & 12.9 & 344 & & \\
\hline 3 & 8.0 & 43 & & & 8.2 & 218 & & \\
\hline 4 & 8.2 & 44 & & & 6.1 & 162 & & \\
\hline 5 & 2.8 & 15 & & & 7.0 & 188 & & \\
\hline $6-10$ & 10.8 & 57 & & & 6.9 & 183 & & \\
\hline $11-20$ & 5.6 & 30 & & & 3.0 & 81 & & \\
\hline 21 or more & 2.2 & 12 & & & 0.7 & 19 & & \\
\hline \multicolumn{9}{|c|}{ Movies attended in last 6 months } \\
\hline None & 53.2 & 283 & & & 68.2 & 1819 & & \\
\hline 1 & 22.6 & 121 & & & 15.1 & 402 & & \\
\hline 2 & 9.9 & 53 & & & 7.5 & 200 & & \\
\hline 3 & 7.6 & 41 & & & 3.3 & 87 & & \\
\hline 4 & 3.2 & 17 & & & 2.6 & 68 & & \\
\hline 5 & 1.5 & 8 & & & 1.5 & 40 & & \\
\hline $6-10$ & 1.4 & 8 & & & 1.6 & 42 & & \\
\hline $11-20$ & 0.4 & 2 & & & 0.1 & 1 & & \\
\hline 21 or more & 0.1 & 1 & & & 0.3 & 8 & & \\
\hline
\end{tabular}

Note: $0=$ Closest to bush; $10=$ closest to gore.

affiliation, age, and videos. Across the dependent variables only gender, political party affiliation, and the number of videos watched in the last month were present in two of the three models.

Within the Internet data, political knowledge had $22 \%$ of the variance explained by 11 variables: education, newspaper, gender, books, income, TV news, political party affiliation, age, TV viewing, movies, and radio. Gun control had $38 \%$ of variance explained by six variables: political party affiliation, gender, education, ethnicity, movies, and newspaper. For foreign policy, $46 \%$ of the variance was predicted by seven variables: political party affiliation, newspaper, movies, education, income, ethnicity, and TV news viewing. Across the Internet data only party identification, education, income, and movies appear in all three regression models. Variables that appear in two regression models are gender, TV news viewing, and ethnicity.

RQ3 questioned whether social category weighting techniques increase the robustness of findings. This notion is assessed with the weighted multiple regressions for each of the dependent variables: political knowledge, gun control, and foreign policy (Tables 6-8, column 3, respectively).

The CATI data were weighted to match the larger county data. Using stepwise multiple regression with political knowledge as the dependent variable, it was found that $23 \%$ of the variance was predicted by seven variables: newspaper, gender, 
Stepwise regression predicting political knowledge

\begin{tabular}{|c|c|c|c|c|c|c|c|}
\hline & \multicolumn{3}{|l|}{ CATI } & \multicolumn{4}{|l|}{ Internet } \\
\hline & $r$ & $\beta^{\mathrm{ab}}$ & $\begin{array}{l}\text { (County) } \\
\beta^{c}\end{array}$ & $r$ & $\beta^{\mathrm{ad}}$ & $\begin{array}{l}\text { (National) } \\
\beta^{\mathrm{e}}\end{array}$ & $\begin{array}{l}\text { (On-line) } \\
\beta^{t}\end{array}$ \\
\hline Education & $.23^{* * *}$ & ns & ns & $.19^{* * *}$ & $.100^{* * * *}$ & $.09^{* * *}$ & $.18^{* * * *}$ \\
\hline Newspaper & $.28^{* * *}$ & $.105^{*}$ & $.11^{*}$ & $.33^{* * *}$ & $.177^{* * * *}$ & $.18^{* * *}$ & $.12^{* * * *}$ \\
\hline Gender (female) & $-.22^{* * *}$ & $-.203^{* * *}$ & $-.20^{* * *}$ & $-.26^{* * *}$ & $-.162^{* * *}$ & $-.18^{* * *}$ & $-.18^{* * *}$ \\
\hline Books & $.18^{* * *}$ & $.161^{* * *}$ & .16 & $.17^{* * *}$ & $.116^{* * *}$ & $.13^{* * *}$ & $.06^{* *}$ \\
\hline Household income & $.25^{* * *}$ & $.151^{* * * *}$ & $.15^{* *}$ & $.22^{* * *}$ & $.096^{* * *}$ & $.12^{* *}$ & $.07^{* * *}$ \\
\hline TV news & $.12^{* * *}$ & ns & ns & $.15^{* * *}$ & $.083^{* * *}$ & $.09^{* * *}$ & $.09^{* * *}$ \\
\hline Party ID & $.18^{* * *}$ & $.141^{* * *}$ & $.14^{* *}$ & $.13^{* * *}$ & $.099^{* * *}$ & $.08^{* * *}$ & $.06^{* * *}$ \\
\hline Magazine & $.18^{* * *}$ & $.140^{* *}$ & $.14^{* *}$ & $.21^{* * *}$ & ns & ns & ns \\
\hline Age & $.16^{* * *}$ & $.118^{* *}$ & $.12^{*}$ & $.20^{* * *}$ & $.101^{* * *}$ & $.08^{* * *}$ & $.07^{* *}$ \\
\hline Videos & $-.11^{*}$ & $-.117^{* *}$ & ns & $.06^{* * *}$ & ns & ns & ns \\
\hline TV & $.11^{*}$ & ns & $\mathrm{ns}$ & .02 & $.060^{* *}$ & $.06^{* *}$ & $.05^{*}$ \\
\hline Movies & -.06 & ns & ns & $.11^{* * *}$ & $.058^{* *}$ & $.05^{*}$ & ns \\
\hline Radio & -.05 & ns & $\mathrm{ns}$ & $.09^{* * *}$ & $.050^{* *}$ & ns & ns \\
\hline$R^{2}$ & & .23 & .23 & & .22 & .21 & .16 \\
\hline
\end{tabular}

Note: ${ }^{*}=p<=.05 ;{ }^{* *} p=<=.01 ;{ }^{* * *} p=<=.001$.

a Unweighted regression.

b F value of $115.97(\mathrm{df}=8,418)$ with $p<=.001$.

c F value of $55.32(\mathrm{df}=7,2189)$ with $p<=.001$.

d F value of 15.97 ( $\mathrm{df}=11,418$ ) with $p<=.001$.

e $F$ value of 62.9 (df $=10,2326$ ) with $p<=.001$

${ }^{\mathrm{f}} \mathrm{F}$ value of 42.3 (df $=9,1968$ ) with $p<=.001$.

Table 7

Stepwise regression predicting closeness to democratic candidate (gore) on the gun control

\begin{tabular}{|c|c|c|c|c|c|c|c|}
\hline & \multicolumn{3}{|l|}{ CATl } & \multicolumn{4}{|l|}{ lnternet } \\
\hline & $r$ & $\beta^{\mathrm{ab}}$ & $\begin{array}{l}\text { (County) } \\
\beta^{c}\end{array}$ & $r$ & $\beta \mathrm{a}^{\mathrm{d}}$ & $\begin{array}{l}\text { (National) } \\
\beta^{e}\end{array}$ & $\begin{array}{l}\text { (On-line) } \\
\beta^{\mathrm{f}}\end{array}$ \\
\hline Party ID & $-.40^{* * *}$ & ns & $-.37^{* * *}$ & $-.58^{* * *}$ & $-.58^{* * *}$ & $-.58^{* * *}$ & $-.57^{* * *}$ \\
\hline Age & $.25^{* *}$ & ns & $.23^{* * *}$ & -.03 & ns & ns & ns \\
\hline TV & -.07 & ns & $-.10^{*}$ & $-05^{*}$ & ns & ns & ns \\
\hline Income & -.08 & ns & $.17^{* * *}$ & -.02 & ns & ns & $.05^{* *}$ \\
\hline Gender (Female) & $.10^{*}$ & $.154^{* * * *}$ & $.11^{*}$ & $.11^{* * * *}$ & $.06^{* * *}$ & $.06^{* *}$ & $.08^{* *}$ \\
\hline Education & .05 & $.136^{* * *}$ & ns & $.017^{* * *}$ & $.17^{* * *}$ & $.17^{* * *}$ & $.06^{* *}$ \\
\hline Ethnicity (White) & $-.15^{* * *}$ & ns & $-.16^{* * * *}$ & $-.05^{*}$ & $.08^{* * *}$ & $.08^{* * *}$ & ns \\
\hline Magazines & .03 & ns & ns & .03 & ns & ns & ns \\
\hline Movies & .06 & ns & $\mathrm{ns}$ & $.05^{*}$ & $.10^{* * *}$ & $.10^{*+*}$ & $.06^{* * * 4}$ \\
\hline Newspaper & $.11^{*}$ & ns & ns & -.04 & $-.58^{* * *}$ & $-.06^{* *}$ & $.05^{* * *}$ \\
\hline Radio & $-.11^{*}$ & ns & ns & -.01 & ns & ns & $-.07^{* *}$ \\
\hline TV News & $.12^{*}$ & $.124^{* *}$ & ns & $-.05^{*}$ & ns & $\mathrm{ns}$ & $.05^{*}$ \\
\hline$R^{2}$ & & .21 & .22 & & .38 & .38 & .37 \\
\hline
\end{tabular}

Note: ${ }^{*}=p<=.05 ;{ }^{* *} p=<=.01 ;{ }^{* * *} p=<=.001$

a Unweighted regression.

${ }^{b}$ F value of $8.18(\mathrm{df}=3,423)$ with $p<=.001$.

c F value of $55.32(\mathrm{df}=6,2189)$ with $p<=.001$.

d F value of 24.19 ( $d f=6,2409)$ with $p<=.001$.

e F value of 222.7 ( $\mathrm{df}=6,2219$ ) with $p<=.001$.

if $F$ value of $140.5(\mathrm{df}=8,1913)$ with $p<=.001$.

books, income, political party affiliation, magazine, and age. For the dependent variable gun control, a comparable proportion of variance (21\%) was explained by female gender, education and TV news exposure. In the final model-predicting closeness to the Democratic candidate on foreign policies-the model explained $24 \%$ of the variance, with use radio and videos as well as White ethnicity emerging as unique predictors.

The data collected via Internet were weighted to match national Census data, and, secondly, to match online user data provided by the US Census. For the national weighting, a stepwise multiple regression with political knowledge as the 
Stepwise regression predicting closeness to democratic candidate (gore) on foreign policies

\begin{tabular}{|c|c|c|c|c|c|c|c|}
\hline & \multicolumn{3}{|l|}{ CATI } & \multicolumn{4}{|l|}{ lnternet } \\
\hline & $r$ & $\beta^{a b}$ & $\begin{array}{l}\text { (County) } \\
\beta^{c}\end{array}$ & $r$ & $\beta^{\text {ad }}$ & $\begin{array}{l}\text { (National) } \\
\beta^{e}\end{array}$ & $\begin{array}{l}\text { (On-line) } \\
\beta^{\mathrm{f}}\end{array}$ \\
\hline Party Id & $-.45^{* \% * 4}$ & $-.54^{* * *}$ & -.543 & $-.64^{* \ldots * *}$ & $-.64^{* * * *}$ & $-.63^{* * * *}$ & $-.62^{* * * *}$ \\
\hline Newspaper & -.01 & ns & ns & $-.06^{* * *}$ & $-.084^{* * *}$ & $-.08^{* * * * *}$ & ns \\
\hline Movies & $.11^{*}$ & ns & ns & $.09^{* * *}$ & $.078^{* * *}$ & $.07^{* * *}$ & $.05^{* * *}$ \\
\hline Education & .02 & ns & ns & .01 & $.180^{* * *}$ & $.06^{* * *}$ & $.09^{* * *}$ \\
\hline Gender (Female) & .07 & ns & ns & $.12^{* *}$ & ns & ns & ns \\
\hline Radio & -.03 & ns & ns & $-.15^{* * *}$ & ns & $-.05^{* *}$ & $-.08^{* * 4}$ \\
\hline Age & $.09^{* * *}$ & $.184^{* * *}$ & $.18^{* * *}$ & -.12 & ns & ns & $.07^{* * *}$ \\
\hline Income & -06 & ns & ns & $-.03^{* * *}$ & $-.122^{* * *}$ & $-.12^{* * *}$ & ns \\
\hline Magazines & -.05 & ns & ns & -.01 & ns & ns & ns \\
\hline Videos & .06 & $.111^{* *}$ & $.11^{*}$ & .02 & ns & $.04^{*}$ & $.05^{*}$ \\
\hline Ethnicity (White) & -.04 & ns & $.06^{* *}$ & $.089^{* * *}$ & $.08^{* * *}$ & & \\
\hline TV News & $.13^{* *}$ & ns & ns & .03 & $.072^{* * *}$ & $.08^{* * * *}$ & \\
\hline TV & .08 & $\mathrm{~ns}$ & $\mathrm{~ns}$ & $-.04^{*}$ & ns & $-.05^{*}$ & \\
\hline$R^{2}$ & & .24 & .24 & & .46 & .46 & .43 \\
\hline
\end{tabular}

Note: ${ }^{*}=p<=.05 ;{ }^{* *} p=<=.01 ;{ }^{* * *} p=<=.001$.

a Unweighted regression.

b $F$ value of $44.27(\mathrm{df}=3.412$ ) and $p<=.001$

c F value of $186.21(\mathrm{df}=4,2217)$ with $p<=.001$.

d F value of 44.3 ( $d f=7,412$ ) with $p<=.001$.

e value of $186.2(\mathrm{df}=9,2217)$ with $p<=.001$.

${ }^{f} \mathrm{~F}$ value of $236.4(\mathrm{df}=6,1914)$ with $p<=.001$.

dependent variable found that $21 \%$ of the variance was predicted by 10 variables: education, newspaper, gender, books, income, TV news, political party affiliation, age, TV, and movies. For the online users weighting, the stepwise regression predicting political knowledge found $16 \%$ of the variance to be predicted by nine variables: education, newspaper, gender, books, income, TV news, political party affiliation, age, and TV.

For the dependent variable gun control, with a weighting to match the national Census, $38 \%$ of the variance was explained by six variables: political party affiliation, gender, education, ethnicity, movies, and newspaper. For gun control, with a weighting to match national online user characteristics, $37 \%$ of the variance was explained by eight variables: political party affiliation, income, gender, education, movies, newspaper, radio, and TV news.

With regard to the dependent variable "closeness to Democratic candidate on foreign policies," with a weighting to match the general US population, $46 \%$ of the variance was explained by nine variables: political party affiliation, newspaper, movies, education, radio, income, videos, TV news, and TV. For that same dependent variable, with the sample weighted to match national online users, $43 \%$ of the variance was explained with six variables: political party affiliation, movies, education, radio, age, and videos.

Comparing the CATI and Internet findings, we see more similarities in the regression equations for weighted vs. unweighted analyses. In an attempt to quantify this observation, simple correlations were calculated for each possible CATI/Internet pairing of standardized regression coefficients. In general, the results confirm greater isomorphism for the weighted analyses. The correlations are as follows:

For political knowledge:

CATI/Internet beta coefficients for unweighted analyses: $r=.74^{* *}$

CATI/Internet beta coefficients for county/national weighted analyses: $r=.76^{* * *}$

CATI/Internet beta coefficients for county/online weighted analyses: $r=.59^{*}$

For gun control:

CATI/Internet beta coefficients for unweighted analyses: $r=.34$ (ns)

CATI/Internet beta coefficients for county/national weighted analyses: $r=.66^{*}$

CATI/Internet beta coefficients for county/online weighted analyses: $r=.75^{\circ *}$

For closeness to democratic candidate on foreign policies:

CATI/Internet beta coefficients for unweighted analyses: $r=.86^{* *}$

CATI/Internet beta coefficients for county/national weighted analyses: $r=.91^{* *}$

CATI/Internet beta coefficients for county/online weighted analyses: $r=.95^{\text {*.* }}$

In all instances except one (the CATI/Internet beta coefficients for county/online weighted analyses of political knowledge), the weighted analyses are more similar between the CATI and Internet administrations than are the unweighted analyses. The results indicate that weighting to match parametric characteristics does seem to increase cross-modal robustness of findings. 


\section{Discussion}

The present study set out to assess the relative advantages and disadvantages of technology-assisted and phone surveys, both of which present important windows into the minds of a population that's increasingly more "connected" - via wired and wireless modalities - in leisure as well as workplace and consumer domains (Brown, 2006). As noted earlier, researchers are in need of more sophisticated and facile weighting algorithms for multivariate weighting processes. This study has indicated that weighting in an attempt to achieve parametric matching does seem to increase the robustness of relationships, and in this age of poor response rates (Adler and Clark, 2001), this seems to demand an increased use of parametric weightings. As it stands, SPSS allows only a single weighting factor, the construction of which may be problematic when the desired weighting variables are interrelated.

Additionally, the range of parametric information available is quite limited at the present time. For our survey-to-county match, only four demographic variables were available, and no media variables were accessible through census or other reliable sources. Further such information might be available from commercial sources (e.g., those that specialize in "single source data" collection and compilation), but their use is restricted to paying clients.

Bearing these constraints in mind, we ran simple correlations between sets of beta coefficients as an indicator of the "robustness" of the present findings. A preliminary application of this technique seems to support the notion that social category weighting increases the "robustness" (i.e., similarity of beta patterns) of findings. Our analyses reveal only one exception - the Internet weighting for one DV (political knowledge). The other five comparisons show higher correlations after weighting.

More sophisticated analyses may shed additional light on the finding of modestly increased robustness with parametric matching. For example, the use of multi-group multiple regression or multi-group structural equation modeling (using either maximum-likelihood or generalized least squares solutions; Byrne, 2001) would allow the testing of the hypothesis that a given predictive model is invariant across samples, by testing the stability of the regression coefficients under constrained and unconstrained conditions. This process may further illuminate the value - and the limitations - of parametric matching.

The present findings should help inform that matching process, as survey researchers come under greater pressure in the face of declining response rates. Ironically, the decades-long slide in survey response rates has been matched by increased diffusion of the very telematic technologies that can help realize the timely, comprehensive and even mobile plebiscites (e.g. Cho and LaRose, 1999). And just as the possible bias resulting from the omission of phone or Internet non-adopters presents a validity threat to survey research, researchers need to be aware of demographic bias among the more than $6 \%$ of US households that use their cell phone as a substitute for landline service (Brown, 2006). Here, as with landline non-coverage, researchers can adjust for possible biases by treating households that now have the service - but have recently been without it - as representative of the households not reached because they are currently without phone service (Kemph and Remington, 2007). Simply including cell numbers in telephone surveys represents another option to increase inclusivity. However, the possible over-sampling of individuals or cohorts receiving landline as well as cell service creates another confound that works against this option.

Even though the diffusion of the Internet is helping to realize the "wired nation" potential envisaged by futurists over 30 years ago (e.g., Smith, 1972), some of its constituent elements (e.g., SPAM, Phishing) undermine the public will to participate in online surveys (Cho and LaRose, 1999). Other innovations, including caller ID and screening devices - presented via telephonic or online modalities - represent further threats to survey validity in those domains. It will be important, then, to further profile respondents in various survey domains relative to the larger population parameters that they have been selected to represent.

Although daunting, such challenges are not without precedent. Since the 1980 s, the television industry has been forced to reconceptualize the survey methodologies underpinning their program ratings which - although not strictly analogous to the parameters considered here - implicate similar validity concerns and remedies. In that case, advertisers realized that many respondents willing to participate in Nielsen's telephone and Peoplemeter survey were heavier, more committed viewers than the general viewing public that they were selected to represent (e.g., Abelman and Atkin, 2002). Industry researchers were able to account for corresponding response bias through assessment of respondent features via stratified weighting, in light of socio-demographics as well as some of the psychometric and media use variables considered here. Practitioners concerned about demographic biases in telephone or Internet respondent bases might consider similar remedies in order to enhance survey validity of those domains.

The importance of these cross-sectional examinations of population subgroups extends far beyond the commercial sector, however, as Kemph and Remington (2007) recount their importance in tracking trends in the prevalence of conditions and risk factors over time, evaluating the effects of interventions, and exploring risk factors associated with numerous health conditions. Although the statistical remedies suggested here can help fill in some of external validity threats - including under-sampling resulting from number portability, cell phones and various screening programs - researchers still need to address the underlying issue of respondent willingness to participate in surveys. Just as privacy advocates have mounted campaigns to make Internet users aware of the risks of sharing private information on the internet, including survey responses that can be indefinitely stored and forwarded, scientific pollsters will need to enhance respondent literacy about the risks and benefits of participating in telematic surveys (Neuendorf et al., 2002). This might include, for instance, the equivalent of a "good housekeeping seal of approval" provided by professional researcher consortia (e.g., Gollin, 1992) or Institutional Review boards. Other, more conventional remedies to the problem of declining participation include adjust- 
ments to the survey script or introduction, the provision of advance notice (e.g., media, electronic or snail-mail channels) and the provision of incentives (see Stempel et al., 2003).

Such measures will be particularly important as the gap between scientific and promotional polls continues to converge, alongside the media modalities through which they're presented. Yet despite the validity threats posed by this proliferation of telematic (and survey) technologies, it is important to recall that these advances provide opportunities to researchers as well, one to which the public and private sectors will continue to provide solutions. Wireless technologies, for instance, now render respondents accessible to researchers at more times and locations than ever before. Hopefully the present results can shed additional light on the challenges and possible remedies for addressing an increasingly poll-wary - and evasive - survey public.

\section{References}

Abelman, R., Atkin, D., 2002. The Televiewing Audience: The Art and Science of Watching Television. Hampton, Cresskill, N] Adler, E.S., Clark, R., 2001. How It's Done: An Invitation to Social Research. Wadsworth, New York.

Atkin, D.J., Jeffres, L.W., Neuendorf, K.A., 1998. Understanding Internet adoption as telecommunications behavior. Journal of Broadcasting and Electronic Media 42, 475-490.

Atkin, D., LaRose, R., 1994a. An analysis of the information services adoption literature. In: Hanson, J. (Ed.), Advances in Telematics, vol. 2. Ablex, Norwood, NJ, pp. 91-110.

Atkin, D., LaRose, R, 1994b. Profiling call-in poll users. Journal of Broadcasting \& Electronic Media 38, $217-227$.

Bassili, J.N., 2000. Editor's introduction: reflections on response latency measurement in telephone surveys. Political Psychology 21 (1), 1-6.

Bates, B.J., Harmon, M., November 1991. Prodigy goes to war: public opinion and videotext polling during the Persian Gulf War. Paper presented at the annual Meeting of the Midwest Association of Public Opinion Research, Chicago.

Bates, B.J., Harmon, M., 1993. Do 'instant polls' hit the spot? Phone-in vs. random sampling of public opinion. Journalism Quarterly $70,369-380$.

Bates, B., Harmon, M., 1999. Do instant polls hit the spot phone-in vs. random sampling of public opinion. In: Adler, E.S., Clark, R. (Eds.), How It's Done: An Invitation to Social Research (Chapter 5). Wadsworth Publishing Co., New York.

Bates, B.J., Albright, K., Washington, K.D., 2002. The difficult world of predicting telecommunication innovations: factors affecting adoption. In: Lin, C., Atkin, D. (Eds.), Communication Technology and Society: Audience Adoption and Uses. Hampton, Creskill, NJ, pp. 91-124.

Bennett, D.J., Steel, D., 2000. An evaluation of large-scale CATl household survey using random digit dialing. Australia and New Zealand Journal of Statistics $42,255-270$

Bonnel, P., LeNir, M., 1998. The quality of survey data: telephone versus face-to-face interviews. Transportation $25,147-167$.

Brown, D., 2006. Communication technology timeline. In: Grant, A., Meadows, J. (Eds.), Communication Technology Update. Focal, Burlington, MA, pp. 7-48.

Byrne, B.M., 2001. Structural Equation Modeling with AMOS: Basic Concepts, Applications, and Programming. Lawrence Erlbaum Associates, Publishers, Mahwah, NJ.

Cho, H., LaRose, R., 1999. Privacy issues in Internet surveys. Social Science Computer Review 17, 421-434.

Cohen, J., Cohen, P., West, S.G., Aiken, L.S., 2003. Applied MultipleRegression/Correlation Analysis for the Behavioral Sciences, 3rd ed. Lawrence Erlbaum Associates, Publishers, Mahwah, NJ.

Dillman, D.A., 2000. The role of behavioral survey methodologists in national statistical agencies. International Statistical Review 68 (2), $200-213$.

Dunn, D.M., Williams, W.H., Spivey, W.A., 1971. Analysis and prediction of telephone demand in local geographic areas. Bell Journal of Economics and Management Science 2, 561-576.

Ford, E.S., 1998. Characteristics of survey participants with and without a telephone: findings from the third national health and nutrition examination survey. Journal of Clinical Epidemiology 51, 55-60.

Fowler Jr., F.J., Roman, A.M., Di, Z.X., 1998. Mode effects in a survey of Medicare prostate surgery patients. Public Opinion Quarterly 62, $29-46$.

Gollin, A.E., 1992. AAPOR backs RIC statements on call-in "polls". AAPOR News 20, 1-2.

Goyder, J., 1985. Face-to-face interviews and mailed questionnaires: the net difference in response rate. Public Opinion Quarterly 49 (2), $234-252$.

Herzog, A.R., Rodgers, W.L., 1988. Interviewing older adults: mode comparison using data from a face-to-face survey and a telephone resurvey. Public Opinion Quarterly 52, 84-99.

Jeffres, L.W., Lee, J., Neuendorf, K., Atkin, D.J., 2007. Newspaper reading, civic values and community social capital. Newspaper Research Journal 28, 6-23.

Jeffres, L.W., Neuendorf, K., Bracken, C., Atkin, D., 2001. Untangling spirals of silence in a presidential election. Presented to the Mass Communication Division at the Annual Conference of the International Communication Association, Washington, DC.

Jones, R., Pitt, N., 1999. Health surveys in the workplace: comparison of postal, email, and World Wide Web methods. Occupational Medicine 49, 556-558.

Kamerer, D., Bergen, L., 1995. Patterns of use, exposure in paper's audiotex system. Newspaper Research Journal 16, 48-59.

Kemph, A.M., Remington, P.L., 2007. New challenges for telephone survey research in the twenty-first century. Annual Review of Public Health $28,113-126$.

Krcmar, M., Strizhakova, Y., 2007. Computer-mediated technology and children. In: Lin, C., Atkin, D. (Eds.), Communication Technology and Social Change: Theory and Implications. LEA, Mahwah, NJ, pp. 59-76.

LaRose, R., Atkin, D., 1988. Cable subscribership as telecommunications behavior. Telematics and lnformatics 5, 105-113.

LaRose, R., Atkin, D., 1992. Audiotext and the reinvention of the telephone as a mass medium. Journalism Quarterly 69, $413-421$

Mahan, G.P., 1979. The Demand for Residential Phone Service. Unpublished Thesis, Michigan State University, East Lansing, MI.

Neuendorf, K.A., Atkin, D., Jeffres, L.W., 1998. Understanding adopters of audio information innovations. Journal of Broadcasting \& Electronic Media 42,80 93.

Neuendorf, K.A., Atkin, D., Jeffres, L.W., 2002. Adoption of audio information services in the United States: a bridge innovation. In: Lin, C.A., Atkin, D.J. (Eds.), Communication Technology and Society: Audience Adoption and Uses. Hampton Press, Cresskill, NJ, pp. $125-152$.

Perl, L.J., 1978. Economic and Demographic Determinants of Residential Demand for Basic Telephone Service. National Economic Research Associates, Inc. Pew Research Center. 2007. Survey reports. <www.pewinternet.org/PPF/t/165reportdisplay.asp> (Retrieved 23.12.2007).

Rogers, E.M., 2003. Diffusion of Innovations, fifth ed. Free Press, New York.

Skalski, P., Neuendorf, K.A., Atkin, D., 2006. Predicting support for doctoral programs in media information technologies. Telematics and Informatics (23/24), $332-342$

Smith, R.L., 1972. The Wired Nation: The Electronic Communications Highway. Harper and Row, New York.

Stempel, G.H., Weaver, D.H., Wilhoit, G.C., 2003. Mass Communication Research and Theory. Allyn \& Bacon, Boston.

Taylor, L.P., 1980. Telecommunications Demand: A Survey and Critique. Ballinger Publishing Co, Cambridge, MA.

Thornberry, O.T.J., Massey, J.T., 1988. Trends in United States telephone coverage across time and subgroups. In: Groves, R.M., Biemer, P.P., Lyberg, L.E., Massey, J.T., Nicholls, W.L., Waksberg, J. (Eds.), Telephone Survey Methodology. Wiley, New York, pp. $25-49$.

Train, K.E., McFadden, D.L., Ben-Akiva, M., 1987. The demand for local telephone service: a fully discrete model of residential calling patterns and service choices. Rand Journal of Economics 18, 109-123.

Tucker, C., Brick, J.M., Meekins, B., Morganstein, D., 2004. Household telephone service and usage patterns in the U.S. in 2004. In: Proceedings of Sect. Survey Res. Methods. Am. Stat. Assoc, Alexandria, VA (CD-ROM) 
Weiser, E.B., 2000. Gender differences in Internet use patterns and Internet applications preferences: a two-sample comparison. CyberPsychology and Behavior 3, 167-178.

Witte, J.C., Amoroso, L.M., Howard, P.E.N., 2000. Method and representation in Internet-based survey tools - mobility, community, and cultural identity in Survey 2000. Social Science Computer Review 18, 179-195.

Xu, M., Bates, B.J., Schweitzer, J.C., 1993. The impact of messages on survey participation in answering machine households. Public Opinion Quarterly 57, $232-237$.

Post-print standardized by MSL Academic Endeavors, the imprint of the Michael Schwarts Library at Cleveland State University, 2017 